\title{
HUBUNGAN ANTARA KONTROL DIRI DENGAN KECANDUAN INTERNET PADA REMAJA
}

\section{RELATIONSHIP BETWEEN SELF CONTROL WITH INTERNET ADDICTION IN ADOLESCENTS}

\author{
Astati $^{1}$, Rimba Hamid ${ }^{2}$, \& Citra Marhan ${ }^{3}$ \\ Program Studi Psikologi \\ Fakultas Keguruan dan Ilmu Pendidikan, Universitas Halu Oleo \\ astatiasta39@gmail.com $\underline{1}$, $\underline{\text { rimbahamid@gmail.com }} \underline{2}$, chetramarhan02@gmail.com $^{3}$
}

\begin{abstract}
ABSTRAK : Kecanduan internet dapat diartikan sebagai sindrom yang ditandai oleh individu menghabiskan sejumlah waktu yang sangat banyak dalam menggunakan internet dan tidak mampu mengontrol penggunaannya saat online. Hal ini ditandai rasa senang dengan internet, durasi penggunaan internet terus meningkat, menjadi cemas dan bosan ketika harus melalui beberapa hari tanpa internet. Jika pengguna internet yang memiliki kontrol diri yang tinggi mampu mengatur penggunaan internet sehingga tidak tenggelam dalam internet, mampu menggunakan internet sesuai kebutuhan, mampu memadukan aktivitas online dengan aktivitas-aktivitas lain dalam kehidupannya dan tidak memerlukan internet sebagai tempat untuk melarikan diri dari masalah. Penelitian ini bertujuan untuk mengetahui hubungan antara kontrol diri dengan kecanduan internet pada remaja di SMPN 3 Bau-Bau. Subjek penelitian ini adalah 37 siswa di SMPN 3 Bau-Bau dengan teknik simple random sampling. Penelitian ini merupakan penelitian kuantitatif korelasional. Pengumpulan data dilakukan dengan menggunakan skala kontrol diri dan skala kecanduan internet. Hasil analisis korelasi Product Moment Pearson menunjukkan bahwa terdapat hubungan antara kontrol diri dengan kecanduan internet pada remaja $(p=0,003<0,05)$ dan $r=-0,469$ yang artinya semakin rendah kontrol diri maka semakin tinggi kemungkinan kecanduan internet.
\end{abstract}

Kata Kunci : kontrol diri, kecanduan, internet, remaja

\begin{abstract}
Internet addiction can be defined as a syndrome characterized by individuals spending a very large amount of time using the internet and not being able to control their use online. This is indicated by feeling happy with the internet, the duration of internet use continues to increase, becoming anxious and bored when having to go through several days without the internet. If internet users who have high self-control are able to regulate internet usage so that they are not immersed in the internet, are able to use the internet as needed, are able to combine online activities with other activities in their lives and do not need the internet as a place to escape from problems. This study aims to determine the relationship between self-control and internet addiction in adolescents at SMPN 3 Bau-Bau. The subjects of this study were 37 students at SMPN 3 Bau-Bau with simple random sampling technique. This research is a correlational quantitative research. The data were collected using a self-control scale and an internet addiction scale. The result of Pearson Product Moment correlation analysis shows that there is a relationship between self-control and internet addiction in adolescents $(\mathrm{p}=0.003<0.05)$ and $\mathrm{r}=-0.469$ which means that the lower self-control, the higher the likelihood of internet addiction.
\end{abstract}

Keywords: self-control, addiction, internet, adolescents 


\section{Pendahuluan}

Internet merupakan salah satu media yang sekarang ini diminati oleh banyak orang. Internet juga tidak hanya memberikan informasi, banyak sekali keuntungan lain dari internet yang dapat diperoleh, misalnya game online, juga beberapa alamat website yang menyuguhkan media untuk berinteraksi dengan orang lain dimana pun seperti $e$ - mail, facebook, youtube dan lain-lain. Dapat dipastikan bahwa jumlah pengguna internet ini akan terus bertambah, dimana internet dapat diakses dengan mudah dengan adanya koneksi dan dapat dibuka melalui gadget seperti smartphone, komputer, dan tablet (Elia, 2009).

Data yang dikeluarkan APJII (Asosiasi Pengguna Jasa Internet Indonesia) menyebutkan pengguna internet di Indonesia sebesar 171,17 juta jiwa dari total 264,16 juta jiwa. Pada kenyataannya kemudahankemudahan yang diberikan internet secara tidak langsung membuat individu tahan berlama-lama berhadapan dengan komputer ataupun smartphone-nya. Penggunaan internet yang mengalami peningkatan dalam intensitas waktu penggunaan yang cukup lama akan menimbulkan berbagai permasalahan yang dikenal sebagai kecanduan internet.

$$
\text { Young (dalam Basri, 2014) }
$$
mengemukakan bahwa kecanduan internet dapat diartikan sebagai sindrom yang ditandai oleh individu menghabiskan sejumlah waktu yang sangat banyak dalam menggunakan internet dan tidak mampu mengontrol penggunaannya saat online. Individu yang dapat dikategorikan kecanduan internet adalah individu yang menghabiskan lebih dari 7 jam dalam satu hari untuk mengakses internet, itu berarti bahwa waktu mengakses internet sama atau bahkan lebih dari jam tidur individu dalam satu hari (Hasanuddin, 2014).

Hal ini berdasarkan hasil pengamatan dan wawancara terhadap siswa di SMP Negeri 3 Bau-Bau pada tanggal 6 Januari 2020, dimana peneliti menemukan bahwa hampir seluruh dari jumlah siswa SMPN 3 Bau-Bau menggunakan internet hanya sebagai sarana informasi dan sarana hiburan. Sebanyak 52 siswa berjenis kelamin lakilaki dalam mengakses internet seperti media sosial, game online dan menonton youtube berdurasi 7 jam dalam satu hari. Sedangkan sebanyak 65 siswa berjenis kelamin perempuan senang bermain media sosial, menonton youtube berdurasi 7 jam dalam sehari.

Widiana, Retnowati dan Hidayat (2004) juga menyebutkan seorang pecandu internet akan menghabiskan waktu berjamjam bahkan secara ekstrem berhari-hari berada di depan komputer untuk online/aktif dalam mengakses internet. Individu yang mengalami kecanduan internet akan merasa bahwa dunia maya di layar komputernya atau smartphonenya lebih menarik dibandingkan dengan kehidupan nyata sehari-hari (Orzack dalam Setiawan, Dwikurnaningsih \& Setyorini, 2019).

Penggunaan yang secara berlebihan tersebut, dapat dikategorikan ke dalam gangguan Internet Addiction Disorder (IAD) atau gangguan kecanduan internet meliputi segala macam hal yang berhubungan dengan internet seperti jejaring sosial, email, pornografi, judi online, game online, chatting dan lain-lain. Griffiths (2000) menyatakan bahwa kecanduan internet belum di akui dalam DSM V, meskipun telah ada pembicaraan mengenai hal tersebut dan fenomena kecanduan. Selain itu American Psychological Association (APA) secara formal menyebutkan bahwa kecanduan ini termasuk dalam salah satu bentuk gangguan (Siwi 2004).

Hal ini sesuai dengan penelitian Hapsari \& Ariana yang mengemukakan hampir $80 \%$ remaja berusia 10-19 tahun yang tersebar di 11 provinsi di Indonesia kecanduan internet, dan sebagian besar remaja menggunakan internet untuk halhal yang tidak semestinya, 24\% mengaku menggunakan internet untuk berinteraksi dengan orang yang tidak dikenal, 14\% 
mengakses konten pornografi, dan sisanya untuk game online dan kepentingan lainnya. Dimana remaja dalam menggunakan internet menghabiskan waktu berjam-jam lamanya bahkan secara ekstrem berhari-hari berada di depan komputer untuk online (Widiana, Retnowati dan Hidayat, 2004).

Remaja yang menghabiskan waktu berjam-jam lamanya hingga mengalami kecanduan internet dapat mengakibatkan efek samping yang cukup besar pada kehidupan remaja, seperti kecemasan, penurunan fisik dan kesehatan mental, hubungan interpersonal, penurunan kinerja dan mengakibatkan kegagalan akademis. Kenyataannya $58 \%$ remaja mengalami penurunan dalam kebiasaan belajar, penurunan ranking, membolos atau mendapatkan masa percobaan disebabkan karena penggunaan internet yang berlebihan. Hal tersebut disebabkan karena remaja mengakses aplikasi yang tidak relefan dengan pelajaran (Young dalam Basri, 2014).

Hal tersebut di atas sejalan dengan hasil wawancara kepada dua orang siswa di SMPN 3 Bau-Bau yang berinisial AN dan YN. AN merasa cemas dan panik ketika baterai yang ia gunakan akan lowbat pada saat menonton video game. YN mengatakan bahwa ketika sedang ada masalah YN selalu melampiaskannya dengan cara online di sosial media dan bermain game online. YN pun merasa kesal ketika ada orang yang mengganggu dan melarangnya saat bermain internet.

Selanjutnya, fenomena ini diperkuat dengan data angket survey awal terhadap siswa di SMP Negeri 3 Bau-Bau yang dilakukan oleh peneliti, dimana sebanyak 107 siswa merasa cemas jika selama 1 jam tidak mengakses internet dan sebanyak 84 siswa mengalami penurunan dalam kebiasaan belajar akibat penggunaan internet yang berlebihan, sebanyak 56 siswa ketika bermain internet mengaku berdampak pada hubungan interpersonalnya saat berkumpul dengan teman dan lebih memilih mengasikkan dirinya dengan gadget untuk membuka situs internet, sebanyak 44 siswa dalam bermain internet berdampak pada penurunan ranking dan depresi ketika akses internet tidak berfungsi, menyembunyikan penggunaan internet dari keluarga.

Yanuar

(Setiawan,

Dwikurnaningsih dan Setyorini, 2019) mengatakan bahwa secara umum ada dua faktor yang mempengaruhi kecanduan internet, yaitu faktor ekstern dan intern. Faktor ekstern seperti lingkungan keluarga, sosial, dan budaya. Faktor intern merupakan faktor yang berasal dari dalam diri individu seperti kepribadian, kontrol diri, minat, motif, pengetahuan, dan usia. Kontrol diri menurut Ghufron dan Risnawati (2010) diartikan sebagai kemampuan untuk menyusun, membimbing, mengatur dan mengarahkan bentuk perilaku yang dapat membawa ke arah konsekuensi positif. Kontrol diri pada satu individu dengan individu yang lain tidaklah sama. Ada individu yang memiliki kontrol diri yang tinggi dan ada individu yang memiliki kontrol diri yang rendah.

Remaja yang memiliki kontrol diri yang tinggi mampu mengubah kejadian dan menjadi agen utama dalam mengarahkan dan mengatur perilaku utama yang membawa pada konsekuensi positif. Pengguna internet yang memiliki kontrol diri yang tinggi mampu mengatur penggunaan internet sehingga tidak tenggelam dalam internet, mampu menggunakan internet sesuai kebutuhan, mampu memadukan aktivitas online dengan aktivitas-aktivitas lain dalam kehidupannya. Pengguna internet dengan kontrol diri yang tinggi tidak memerlukan internet sebagai tempat untuk melarikan diri dari masalah. Menurut Ghufron dan Risnawati (dalam Shohibullana, 2014), kontrol diri dipengaruhi oleh faktor internal dan faktor eksternal yang juga meliputi beberapa aspek yaitu aspek kontrol perilaku (behaviorcontrol), kontrol kognitif (cognitive control), dan mengontrol keputusan (decisional control). 
Pengguna internet dengan kontrol diri rendah tidak mampu mengatur penggunaan internet sehingga perhatian tertuju hanya pada internet, berharap untuk segera online atau memikirkan aktivitas online. Pengguna internet dengan kontrol diri rendah dapat menghabiskan waktu berjam-jam dengan aktivitas online hingga melupakan bagian lain dari kehidupannya seperti waktu belajar, bekerja, dan bersosialisasi dengan orang lain, bahkan menggunakan internet sebagai tempat untuk melarikan diri dari masalah (Widiana, Retnowati dan Hidayat, 2004).

Dari pemaparan di atas, hal ini sesuai dengan penelitian-penelitian sebelumnya yang dilakukan oleh Widiana, dkk (2004) yang menunjukkan adanya hubungan negatif antara kontrol diri dengan kecenderungan internet, dimana individu yang mempunyai kontrol diri tinggi maka akan mampu mengarahkan dan membatasi perilaku menggunakan internet dengan memikirkan manfaat dan dampak yang ditimbulkan. Sama halnya dengan penelitian yang dilakukan oleh Arisandy (2009) tentang hubungan antara kontrol diri dengan kecanduan internet pada mahasiswa Universitas Bina Darma Palembang, ada hubungan negatif antara kecanduan internet dengan kontrol diri pada mahasiswa Universitas Bina Darma Palembang. Hal ini berarti, semakin tinggi kecanduan internet maka semakin rendah tingkat kontrol diri, sebaliknya semakin rendah kecanduan internet maka semakin tinggi tingkat kontrol diri.

Berdasarkan data lapangan yang diperkuat dari hasil data angket survey awal yang telah peneliti lakukan pada tanggal 6 Januari 2020 dan dibagikan kepada 640 siswa SMPN 3 Bau-Bau, menunjukkan bahwa remaja di SMP Negeri 3 Bau-Bau dari keseluruhannya menggunakan jasa internet. Seluruh subjek memberikan jawaban yang beragam mengenai apa yang mereka lakukan saat bermain internet seperti mencari informasi yang diinginkan, bermain game online, menonton youtube, mencari referensi tugas sekolah, membaca novel, membaca berita, chatting, dan aktivitas sosial media lainnya. Kemudian peneliti mendapatkan beragam jawaban dari siswa mengenai waktu yang telah mereka habiskan untuk mengakses internet, sebanyak 113 siswa dalam mengakses internet selama 7 jam, 107 siswa merasa cemas jika selama 1 jam tidak mengakses internet dan sebanyak 84 siswa mengalami penurunan dalam kebiasaan belajar akibat penggunaan internet yang berlebihan, sebanyak 98 siswa berbohong kepada orang tua untuk membeli kuota internet dan lebih memilih bermain internet daripada keluar dengan teman-teman.

Adapun tujuan dari penelitian ini yaitu untuk mengetahui hubungan antara kontrol diri dengan kecanduan internet pada remaja siswa SMP Negeri 3 Bau-Bau. Manfaat penelitian terdiri dari:

Manfaat Teoritis

Hasil penelitian ini diharapkan menjadi sumber informasi bagi mahasiswa, khususnya mahasiswa psikologi dalam melakukan penelitian selanjutnya.

Manfaat praktis yang diharapkan dari penelitian ini adalah agar bisa menjadikan bahan pertimbangan dalam mengakses internet dengan bijaksana, sehingga tidak akan ada rasa cemas yang timbul dan menjadikan para remaja kecanduan internet.

\section{Metode Penelitian}

Kontrol diri adalah kemampuan

siswa untuk menolak atau mengubah respon inti pada diri serta kemampuan untuk menyela dan mengendalikan kecenderungan perilaku online yang tidak diinginkan, sehingga dapat menahan diri dari melakukan perilaku tersebut untuk mendapatkan konsekuensi positif dan menghindari konsekuensi negatif. Sedangkan kecanduan internet adalah suatu tingkah laku dimana siswa yang mengalami ketergantungan tanpa menggunakan obat-obatan terhadap penggunaan internet yang ditandai dengan menghabiskan waktu 7 jam dalam menggunakan internet dan menimbulkan 
perasaan senang, serta tidak mampu mengontrol penggunaannya sehingga menimbulkan perasaan yang tidak menyenangkan saat tidak dapat menggunakan internet.

Penelitian ini dilakukan di SMPN 3

Bau-Bau yang beralamat di jalan Betoambari No. 71. Jenis penelitian adalah penelitian kuantitatif dengan desain penelitian yang digunakan adalah korelasional. Populasi dalam penelitian ini berjumlah 132 siswa. Hasil tersebut didapatkan dari screening berupa angket yang dilakukan peneliti di SMPN 3 Bau- Bau. Subjek penelitian ditetapkan untuk diambil $25 \%$ secara random sebagai sampel dari populasi yang berjumlah 132 siswa dengan menggunakan teknik simple random sampling.

Metode pengumpulan data melalui penyebaran skala, uji validitas dan uji reliabilitas. Skala ini terdiri dari dua macam yaitu skala kontrol diri dan skala kecanduan internet. Metode skala yang digunakan adalah skala Likert, terdiri dari pernyataan-pernyataan yang bersifat favorabel dan unfavorabel.

Analisis yang digunakan dalam penelitian ini yaitu analisis deskriptif, untuk memberikan deskripsi mengenai data dari variabel yang diukur dan analisis data inferensial, untuk mengetahui apakah data terdistribusi secara normal yakni menggunakan teknik Kolmogorof-Smirnov dan apakah jenis data tersebut linear yakni menggunakan test for linearity, adapun uji hipotesis, dalam penelitian ini menggunakan korelasi product moment

pearson.

\section{Hasil Penelitian dan Pembahasan Hasil Penelitian}

Uji normalitas menunjukkan nilai signifikansi sebesar 0,794. Nilai ini lebih besar dari 0,05, ini menunjukkan bahwa data variabel kontrol diri dan variabel kecanduan internet terdistribusi secara normal.
Tabel 1. Hasil Uji Normalitas

\begin{tabular}{|c|c|c|}
\hline $\begin{array}{l}\text { Kariabel } \\
\text { Smirnov }\end{array}$ & Kolmogorov- & Signifikansi \\
\hline Kontrol diri & 0.649 & 0.794 \\
\hline $\begin{array}{l}\text { Kecanduan } \\
\text { Internet }\end{array}$ & 0.649 & 0.794 \\
\hline
\end{tabular}

Uji linearitas menunjukkan nilai signifikansi deviation from linearity sebesar 0,093. Nilai ini lebih besar dari 0,05 , ini menunjukkan bahwa data variabel kontrol diri dan variabel kecanduan internet mempunyai hubungan yang linear. Artinya, setiap perubahan yang terjadi pada satu variabel akan diikuti perubahan dengan besaran yang sejajar pada variabel lainnya.

Tabel 2. Uji Linearitas

\begin{tabular}{|c|c|c|}
\hline Variabel & $\begin{array}{l}\text { Sig. } \\
\text { Linearit } \\
y\end{array}$ & $\begin{array}{l}\text { Signifikansi } \\
\text { Deviation from } \\
\text { Linearity }\end{array}$ \\
\hline $\begin{array}{l}\text { Kontrol Diri } \\
\text { dan } \\
\text { Kecanduan } \\
\text { Internet }\end{array}$ & 0.001 & 0.093 \\
\hline
\end{tabular}

Variabel kontrol diri mempunyai nilai empirik maximum sebesar 113 dan nilai empirik minimum sebesar 56, sehingga didapati nilai mean empirik pada variabel tersebut sebesar 79,19 dengan standar deviasi empirik sebesar 14,020.

Tabel 3. Mean empirik dan standar deviasi empirik kontrol diri

\begin{tabular}{|c|c|c|c|c|c|}
\hline $\begin{array}{l}\text { Variab } \\
\text { el }\end{array}$ & $\begin{array}{l}M i \\
n\end{array}$ & $\begin{array}{l}M a \\
x\end{array}$ & $\begin{array}{l}\text { Mea } \\
n\end{array}$ & $\begin{array}{l}\text { Standa } \\
r \\
\text { Devias } \\
i\end{array}$ & $\mathbf{N}$ \\
\hline $\begin{array}{l}\text { Kontrol } \\
\text { Diri }\end{array}$ & 56 & 113 & $\begin{array}{l}79.1 \\
9\end{array}$ & 14.020 & 3 \\
\hline
\end{tabular}

Berdasarkan hasil dari skor tersebut dapat dijadikan kriteria berjenjang dengan menggunakan norma pengkategorisasian yang dapat dilihat sebagai berikut: 
Tabel 4. Kategorisasi Kontrol Diri

\begin{tabular}{|c|c|c|c|}
\hline $\begin{array}{l}\text { Interval } \\
\text { Skor } \\
\end{array}$ & Kategori & Frekuensi & $\begin{array}{l}\text { Persentase } \\
\%\end{array}$ \\
\hline $56-67,4$ & $\begin{array}{l}\text { Sangat } \\
\text { Rendah }\end{array}$ & 6 & 16,2 \\
\hline $67,5-78,8$ & Rendah & 15 & 40,5 \\
\hline $78,9-90,2$ & Sedang & 9 & 24,3 \\
\hline $\begin{array}{l}90,3- \\
101,6\end{array}$ & Tinggi & 2 & 5,4 \\
\hline $101,7-113$ & $\begin{array}{l}\text { Sangat } \\
\text { Tinggi }\end{array}$ & 5 & 13,5 \\
\hline Jumlah & & 37 & 100 \\
\hline
\end{tabular}

Variabel kecanduan internet mempunyai nilai empirik maximum sebesar 145 dan nilai empirik minimum sebesar 68, sehingga didapati nilai mean empirik pada variabel tersebut sebesar

105,49 dengan standar deviasi empirik sebesar 20,227. Berdasarkan hasil dari skor tersebut dapat dijadikan kriteria berjenjang dengan menggunakan norma pengkategorisasian yang dapat dilihat sebagai berikut:

Tabel 5. Mean empirik dan standar deviasi empirik kecanduan internet

\begin{tabular}{|c|c|c|c|c|c|}
\hline $\boldsymbol{M i}_{n}$ & & $\begin{array}{l}M a \\
x\end{array}$ & $\begin{array}{l}\text { Mea } \\
n\end{array}$ & $\begin{array}{l}\text { Stand } \\
\text { ar } \\
\text { Devias } \\
i\end{array}$ & $\boldsymbol{N}$ \\
\hline $\begin{array}{l}\text { Kecandu } \\
\text { an Internet }\end{array}$ & 68 & 145 & $\begin{array}{l}105.4 \\
9\end{array}$ & 20.227 & $\begin{array}{l}3 \\
7\end{array}$ \\
\hline
\end{tabular}

Setelah mengetahui masing-masing tingkat kategorisasi subjek dari kedua variabel, maka dapat disimpulkan rata-rata keduanya berada pada tingkat kategorisasi rendah. Dimana tingkat kontrol diri dengan kecanduan internet mayoritas menghasilkan nilai sebesar $40,5 \%$ dan $29,7 \%$.
Tabel 6. Kategorisasi Kecanduan Internet

\begin{tabular}{|c|c|c|c|}
\hline $\begin{array}{l}\text { Interval } \\
\text { Skor } \\
\end{array}$ & Kategori & Frekuensi & Persentase\% \\
\hline $68-83,4$ & $\begin{array}{l}\text { Sangat } \\
\text { Rendah }\end{array}$ & 6 & 16,2 \\
\hline $\begin{array}{r}83,5- \\
98,8 \\
\end{array}$ & Rendah & 6 & 16,2 \\
\hline $\begin{array}{l}98,9- \\
114,2 \\
\end{array}$ & Sedang & 11 & 29,7 \\
\hline $\begin{array}{r}114,3- \\
129,6 \\
\end{array}$ & Tinggi & 8 & 21,6 \\
\hline $\begin{array}{l}129,7- \\
145\end{array}$ & $\begin{array}{l}\text { Sangat } \\
\text { Tinggi }\end{array}$ & 6 & 16,2 \\
\hline Jumlah & & 37 & 100 \\
\hline
\end{tabular}

Hasil data menunjukkan nilai signifikansi 0,003 . Nilai ini lebih kecil dari 0,05 , sehingga dapat dikatakan bahwa terdapat hubungan kontrol diri secara signifikan terhadap kecanduan internet, dimana arah angka koefisien korelasi hasilnya negatif yakni -0,469. Artinya semakin tinggi kontrol diri maka semakin rendah kecanduan internet dan begitu pula sebaliknya, semakin rendah kontrol diri maka semakin tinggi kecanduan internet.

Tabel 4.7 Hasil Uji Korelasi

\begin{tabular}{lll}
\hline Variabet $^{\text {Korelasi }}$ & Pearson & Signifikansi \\
\cline { 1 - 2 } Kontrol diri & -0.469 & 0,003 \\
\hline $\begin{array}{l}\text { Kecanduan } \\
\text { internet }\end{array}$ & -0.469 & 0,003 \\
\hline
\end{tabular}

\section{Pembahasan}

Hasil penelitian menemukan bahwa analisis korelasi menunjukkan nilai signifikansi sebesar 0,003 $(\mathrm{p}<0,05)$ dan nilai koefisien korelasi sebesar $-0,469$ yang menunjukkan bahwa kontrol diri mempunyai hubungan negatif artinya semakin tinggi kontrol diri maka semakin rendah kecanduan internet, begitu sebaliknya semakin rendah kontrol diri maka semakin tinggi kecanduan internet. Individu yang tidak memiliki kontrol diri yang baik, tidak dapat membatasi intensitas dalam bermain internet.

Hasil ini sejalan dengan penelitian yang dilakukan oleh Ningtyas (2012) 
Vol. 1, No. 3 September 2020

menyebutkan bahwa ada hubungan negatif yang sangat signifikan antara antara self control dengan internet addiction pada mahasiswa FIP semester 5 UNNES. Penelitian tersebut dijelaskan bahwa faktor yang menyebabkan individu menghabiskan banyak waktunya untuk menggunakan internet secara berlebihan disebabkan karena kurangnya kemampuan dan mengontrol emosi serta dorongandorongan dalam diri mereka untuk tidak menggunakan internet secara berlebihan, dan kurang mampu dalam mengambil keputusan atau suatu tindakan yang cukup baik terhadap penggunaan internet.

Sejalan dengan pendapat tersebut, Young (1998) mengungkapkan bahwa remaja sebagai pengguna internet yang memiliki kontrol diri yang tinggi mampu mengatur penggunaan internet sehingga tidak tenggelam dalam menggunakan internet sesuai dengan kebutuhan, tidak memerlukan internet sebagai tempat melarikan diri dari masalah atau menghilangkan perasaan tidak berdaya, merasa bersalah, dan cemas, sedangkan remaja sebagai pengguna internet dengan kontrol diri rendah tidak mampu mengatur penggunaan internet, dapat menghabiskan waktu berjam-jam hanya untuk berjelajah internet sehingga melupakan kehidupan disekitarnya seperti waktu belajar, bekerja, bersosialisasi dengan orang lain dan internet digunakan sebagai tempat melarikan diri dari masalah.

Hal ini didukung oleh Usi \& Hadis (Dyah, 2009) bahwa pecandu internet yang tidak dapat mengontrol diri memiliki kemungkinan untuk mengabaikan kegiatan lainnya, umumnya remaja yang kecanduan internet lupa waktu, sekolah, dan lingkungan sekitar. Kondisi tersebut mengindikasikan bahwa kontrol diri pada subjek rendah. Kemampuan yang dimiliki oleh remaja dalam mengendalikan perilaku dan menahan diri merupakan salah satu faktor yang mampu untuk menghindarkan seseorang dari perilaku kecanduan. Borba (2008) mengatakan bahwa kontrol diri menyebabkan individu mampu untuk mengontrol diri sehingga dapat berperilaku
e-ISSN 2716-1854

p-ISSN 2720-930X

dengan benar dan sesuai berdasarkan hati dan pikiran. Kontrol diri membuat individu menyadari bahwa hal tersebut memiliki konsekuensi berbahaya atas tindakan yang dilakukan agar mampu mengatur emosinya.

Hasil penelitian menunjukkan kontrol diri subjek berada pada kategori rendah, hal ini disebabkan adanya faktor internal yaitu bagaimana individu mampu mengontrol dirinya sendiri dalam bermain internet dan faktor eksternal termasuk diantaranya adalah lingkungan keluarga, dimana dalam lingkungan keluarga terutama orang tua akan menentukan bagaimana kemampuan mengontrol diri subjek terutama dalam bermain internet. Bila orang tua menerapkan kepada anaknya sikap disiplin secara intens sejak dini maka individu mampu mengontrol penggunaannya dalam bermain internet. .

Hasil analisis kategorisasi kecanduan internet menunjukkan kategori tinggi. Tingginya kecanduan internet dipengaruhi oleh keasikkan dengan internet, perlu waktu tambahan, tidak mampu mengontrol penggunaan internet, gagal dalam mengurangi kegiatan internet, mengakses lebih lama, dan menjadikan internet sebagai pelarian dari masalah. Penelitian ini dikuatkan dengan adanya faktor-faktor dari Montag \& Reuter (Hariadi, 2018) yaitu faktor kondisi psikologis dan faktor sosial, dimana kecanduan timbul akibat masalah emosional seperti tekanan akibat tugas, sehingga sering menggunakan dunia fantasi di internet sebagai pengalihan secara psikologis terhadap perasaanperasaan yang tidak menyenangkan atau situasi yang menimbulkan stress, sehingga hal ini menyebabkan individu terdorong untuk lebih sering menggunakan internet sebagai pelampiasan dan akan membuat individu sulit mengontrol waktu pada saat bermain internet.

Hasil penelitian ini juga menemukan bahwa hubungan antara kontrol diri dengan kecanduan internet pada remaja dapat pula di lihat dari item kontrol diri 
yaitu sulit mengontrol dirinya, tidak peduli terhadap apa yang terjadi dengan dirinya sendiri, lalu didukung dengan item kecanduan internet yaitu gelisah atau bosan jika selama 1 jam tidak mengakses internet, dorongan untuk bermain internet selalu muncul, tidak bisa lepas dari bermain internet, marah ketika sinyal hilang. Hal yang di alami oleh subjek adalah, saat ia merasa lelah dan bosan dengan aktivitasnya, ia memilih bermain internet untuk menghilangkan perasaan lelah dan bosan. Walaupun subjek juga merasa takut apabila nantinya dimarahi oleh orang tua, tapi ia tetap memilih untuk

bermain internet dan meninggalkan aktivitas tanpa memikirkan bagaimana konsekuensi yang akan dihadapinya.

Hal ini sesuai dengan pendapat Widiana (2004) bahwa pengguna internet yang memiliki kontrol diri tinggi mampu untuk mengatur perilaku online. Individu yang memiliki kontrol diri yang tinggi mampu mempertimbangkan konsekuensi sehingga mampu memilih tindakan yang dilakukan. Selain itu individu mampu mengatur dalam menggunakan internet sehingga tidak larut dalam internet dan menggunakan internet sesuai dengan kebutuhan, mampu menyeimbangkan aktivitas online dengan aktivitas lain dalam kehidupan. Individu yang memiliki kontrol diri tidak menjadikan internet sebagai tempat untuk melarikan diri dari masalah. Individu dengan kontrol diri yang rendah tidak mampu mengendalikan dirinya, mengarahkan dan mengatur perilaku dalam penggunaan internet. Individu tersebut tidak mampu mempertimbangkan konsekuensi yang dihadapi sehingga tidak mampu memilih tindakan yang dilakukan. Individu dalam menggunakan internet larut dan menggunakan internet sebagai tempat untuk pelarian dari permasalahan.

Hal tersebut sesuai dengan apa yang dialami subjek, dimana awalnya mereka bermain internet hanya untuk mengurangi rasa bosan ketika tidak memiliki kegiatan yang menarik untuk dikerjakan, namun
Dampak dari kecanduan yaitu kurangnya waktu subjek, kurangnya komunikasi tatap muka, dan tidak dapat beraktivitas melainkan setiap kali dia mengasikkan dirinya dengan berbagai fitur menarik di internet, maka subjek tidak mampu mengontrol dirinya.

Secara umum distribusi siswa pada kontrol diri dan kecanduan internet dari pada kategori yang digunakan dapat di lihat pada grafik berikut.

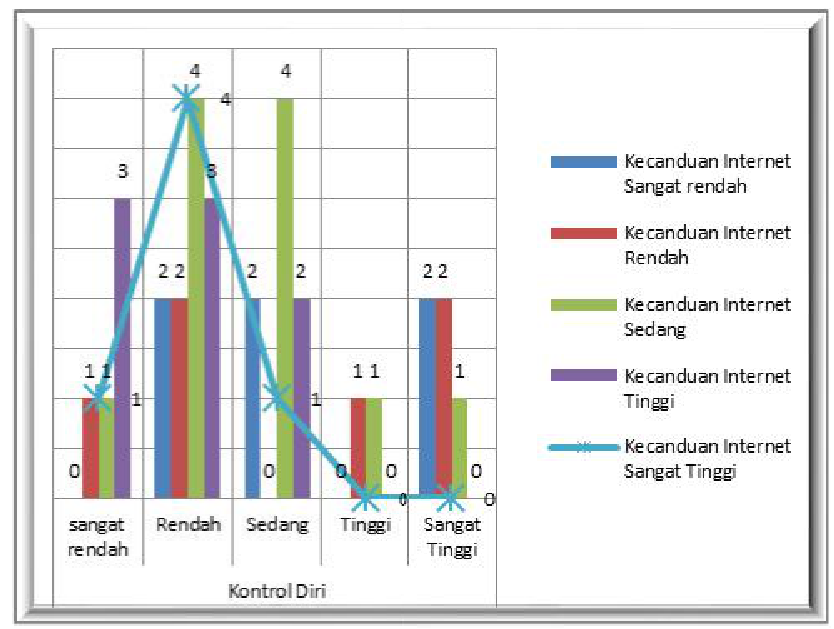

Grafik 1. Kategorisasi kontrol diri dan kecanduan internet

\section{Kesimpulan dan Saran Kesimpulan}

Berdasarkan hasil penelitian yang dilakukan pada siswa SMPN 3 Bau-Bau dapat disimpulkan bahwa hipotesis dalam penelitian ini diterima, yaitu terdapat hubungan negatif antara kontrol diri dengan kecanduan internet pada remaja. Artinya semakin rendah kontrol diri maka semakin tinggi kecanduan internet.

\section{Saran}

Bagi remaja

$$
\text { Diharapkan remaja mampu }
$$

menjaga dan meningkatkan kemampuan kontrol diri dengan cara mengikuti kegiatan ekstrakurikuler di sekolah ataupun di luar sekolah agar mereka bisa memanfaatkan waktu luang dalam kegiatan positif yang bermanfaat, misalnya kegiatan pramuka, ekstrakurikuler olahraga, kesenian maupun keagamaan untuk 
Jurnal SUBLIMAPSI

Vol. 1, No. 3 September 2020

lama kelaman mereka menjadi kecanduan. memanfaatkan waktu luang. Bagi orang tua

Diharapkan anggota keluarga

khususnya orang tua untuk dapat melakukan pengawasan terhadap aktivitasaktivitas yang dilakukan oleh anak dan membatasi penggunaan internet. Ketika anak mencapai usia Sekolah Menengah Pertama, keluarga sangat berperan dalam setiap tugas perkembangan yang akan dicapai oleh siswa.

Bagi peneliti selanjutnnya

Penelitian selanjutnya disarankan agar jumlah item skala nya di kurangi untuk mengantisipasi banyaknya item skala yang gugur atau tidak valid sehingga bisa mewakili dari aspek yang hendak diukur.

Peneliti diharapkan untuk mengkaji lebih banyak sumber maupun referensi mengenai kontrol diri dengan kecanduan internet, mengingat bahwa internet terus mengalami perkembangan dari waktu ke waktu.

\section{Daftar Pustaka}

APJII. (2017). Penetrasi dan Perilaku Pengguna Internet Indonesia. Info grafis Hasil Survey, 1-39.

Arisandy, D. (2009). Hubungan antara Kontrol Diri dengan Kecanduan Internet pada Mahasiswa Universitas Bina Darma Tahun 2009 Palembang. Jurnal Ilmiah, 3(2), 1-13.

Basri, S. H. (2014). Kecanduan Internet Addiction Disorder Mahasiswa Fakultas Dakwah dan Komunikasi ditinjau dari Religiositas. Jurnal Dakwah, 15(2), 407-432.

Borba, M. (2008). Membangun Kecerdasan Moral, Tujuh Kebajikan Utama agar Anak Bermoral Tinggi. Jakarta: PT. Gramedia Pustaka Utama.

Dyah, R. (2009). Hubungan antara Kontrol Diri dengan Kecanduan Internet pada Siswa Sekolah Menengah Pertama. (Skripsi Tidak Dipublikasikan). Fakultas Psikologi Universitas Muhammadiyah Surakarta, Surakarta.

$$
\begin{aligned}
& \text { e-ISSN 2716-1854 } \\
& \text { p-ISSN 2720-930X }
\end{aligned}
$$

Elia, H. (2009). Kecanduan Berinternet dan Prinsip-Prinsip untuk Menolong Pecandu Internet. Jurnal Teologi dan Pelayanan, 10(2), 285-299.

Ghufron \& Risnawita, R. (2010). TeoriTeori Psikologi. Jogjakarta: Ar-Ruzz Media.

Griffiths, M. (2000). Does internet and computer "addiction" exist. Some case study evidence. Cyber Psychology \& Behavior, 3(2), 211- 218. doi: 10.1089/109493100316067

Hariadi, A. F. (2018). Hubungan antara Fear Of Missing Out (Fomo) dengan Kecanduan Media Sosial pada Remaja. (Skripsi). Universitas Islam Negeri Sunan Ampel Surabaya.

Hasanuddin. (2014). $\quad$ http://alvarastrategic.com. Diakses September 2019.

Ningtyas, S. D. Y. (2012). Hubungan antara Self Control dengan Internet Addiction pada Mahasiswa. Education Psychology Journal, 01, 25-30.

Setiawan, G., Dwikurnaningsih, Y., \& Setyorini. (2019). Hubungan Kontrol Diri dengan Kecanduan Internet Siswa Kelas IX SMP Kristen 2 Salatiga. Journal Ilmiah Pendidikan, 10(1), 52-62.

Shohibullana, I. M. (2014). Kontrol Diri dan Perilaku Konsumtif pada Siswa SMA (Ditinjau Dari Lokasi Sekolah). Jurnal Online Psikologi, 2(1), 46-61.

Siwi, H. W. (2000). Hubungan Kontrol Diri dengan Kecenderungan Kecanduan Internet. (Skripsi tidak diterbitkan). Fakultas Psikologi Universitas Gadjah Mada.

Widiana, H.S. (2004). Hubungan antara Pengendalian Diri dengan Kecenderungan Kecanduan Internet. (Skripsi tidak diterbitkan). Fakultas Psikologi UGM, Yogyakarta. 
Widiana, H. S., Retnowati, S., \& Hidayat, R. (2004). Kontrol Diri dan Kecenderungan kecanduan Internet. Indonesian Psychologycal Journal, 1(1), 6-16.

Young, K. (1998). Caught in the Net: How to Recognize the Signs of Internet Addiction and a Winning Strategy for Recovery. New York, NY: Wiley. 